\title{
ANALISIS MISKONSEPSI LITERASI SAINS MENGGUNAKAN THREE TIER MULTIPLE CHOICE TEST MATERI CAHAYA
}

\author{
Sri Wahyuningsih ${ }^{1}$, Ani Rusilowati ${ }^{2}$, Nathan Hindarto ${ }^{3}$ \\ ${ }^{1,2,3,}$ Pascasarjana Universitas Negeri Semarang
}

\begin{abstract}
The aims of this study to develop three tier multiple choice (3TMC) test with the scientific literacy aspect and to find the misconception of students' light scientific literacy. The research sample is class VIIIE and VIIIF with mix method of sequential explanatory strategy. The result of 3TMC test instrument with scientific literacy aspect which is developed which is 30 item where 25 items fulfill criteria with valid result, reliable, sufficient distinguishing, medium difficulty level while 5 grains are not used. The results of the interpretation indicate that the average learners have misconception of scientific literacy aspects of knowledge (A), science investigation competence $(B)$, science as a way of thinking $(C)$ and application of science to technology, society and environment. In-depth interviews were conducted on 7 students who experienced the highest misconception of scientific literacy. The result they experience misconceptions of scientific literacy indicators of light properties, viewing processes, eye defects and optical devices.
\end{abstract}

Keywords: Scientific Literacy Skills, Multiple Choice Test

\begin{abstract}
Abstrak
Tujuan penelitian untuk mengembangkan three tier multiple choice (3TMC) test dengan aspek literasi sains dan menemukan miskonsepsi literasi sains peserta didik materi cahaya. Sampel penelitian yaitu kelas VIIIE dan VIIIF dengan metode campuran (mix method) strategi eksplanatoris sekuensial. Hasilnya instrumen 3TMC test dengan aspek literasi sains yang dikembangkan yaitu 30 butir soal dimana 25 butir memenuhi kriteria dengan hasil valid, reliabel, daya pembeda cukup, tingkat kesukaran sedang sedangkan 5 butir tidak digunakan. Hasil interpretasi menunjukkan bahwa rata-rata peserta didik mengalami miskonsepsi literasi sains aspek pengetahuan (A), kompetensi penyelidikan sains (B), sains sebagai cara berpikir (C) dan aplikasi sains terhadap teknologi, masyarakat dan lingkungan. Wawancara mendalam dilakukan kepada 7 peserta didik yang mengalami miskonsepsi literasi sains tertinggi. Hasilnya mereka mengalami miskonsepsi literasi sains indikator sifat cahaya, proses melihat, cacat mata dan alat optik.
\end{abstract}

Kata kunci: Keterampilan Literasi Sains, Tes Pilihan Ganda 


\section{PENDAHULUAN}

Kemajuan sains dan teknologi di berbagai negara pada abad 21 ini berkembang sangat cepat. Persaingan untuk menunjukkan kualitas dan konsistensi suatu bangsa ditunjukkan dengan kemajuan di bidang ilmu pengetahuan dan teknologi (Ma'muroh, 2014). Caranya dengan meningkatkan sumber daya manusia yang berkualitas agar siap bersaing dan menghadapi tantangan global melalui peningkatan kualitas pembelajaran dalam pendidikan (Rusilowati, 2013). Pembelajaran sains yang rendah dapat diindikasikan dengan rendahnya kemampuan literasi sains peserta didik (Rusilowati et al., 2016).

Pendidikan internasional sekarang sedang berfokus pada pentingnya penguasaan literasi sains sebagai tujuan utama pendidikan EFA (Education For All) oleh UNESCO (Udompong \& Wongwanich, 2014). Peserta didik sebagai warga negara dan konsumen penting untuk memahami literasi sains dalam menanggapi masalah dan isu sains serta pengambilan keputusan yang bertanggung jawab (Alchin, 2014). Literasi sains merupakan kemampuan yang melibatkan isu-isu dan ide-ide terkait sains, hubungan ilmu pengetahuan dan teknologi, kompetensi untuk menjelaskan fenomena ilmiah, mengevaluasi dan mendesain penyelidikan ilmiah, serta menafsirkan data dan bukti ilmiah sebagai warga negara yang reflektif (OECD, 2016).

Kemampuan literasi sains peserta didik di Indonesia sejak tahun 2000 selalu rendah, begitu juga tahun 2015 mendapat peringkat 62 dari 70 negara (OECD, 2016). Sejalan dengan penelitian yang dilakukan oleh Rusilowati et al. (2016) menyatakan bahwa literasi sains peserta didik di SMP Kudus adalah rendah, secara keseluruhan persentase penguasaan literasi sains kurang dari 50\%. Kesulitan belajar IPA pada beberapa materi fisika banyak menimbulkan ketidakpahaman dan kesalahan konsep peserta didik (Sari et al., 2013).

Peserta didik memiliki konsepsi awal berupa pengalaman sehari-hari dan pengetahuan yang pernah diterima kemudian dibawa ke dalam kelas (Franke et al., 2013). Konsepsi awal peserta didik yang tidak sesuai dengan teori yang dirumuskan oleh para ilmuwan disebut miskonsepsi (Clement et al., 1989). Miskonsepsi menjadi masalah besar dalam IPA yang memerlukan penanganan serius karena miskonsepsi bersifat tetap saat tidak terbukti salah atau tidak mendapat pertentangan konsep lain (Taufiq, 2012). 
Identifikasi miskonsepsi dapat dilakukan salah satunya dengan tes diagnostik (Fariyani et al., 2015). Hasil observasi dan wawancara di beberapa sekolah kota Semarang menunjukkan bahwa tes yang dilakukan di sekolah berupa tes pilihan ganda atau uraian. Tes tersebut belum pernah digunakan untuk mengidentifikasi terjadinya miskonsepsi. Sejauh ini guru tidak mengetahui peserta didik yang memperoleh nilai rendah disebabkan mengalami miskonsepsi atau tidak paham konsep.

Hasil wawancara dengan guru di SMP Negeri 05 Semarang menunjukkan adanya kesulitan pada materi cahaya. Nilai UH materi cahaya pada peserta didik yang sudah menerima materi pembelajaran hanya 53\% yang mencapai KKM dan $47 \%$ belum mencapai KKM. Data awal menunjukkan adanya miskonsepsi materi cahaya di SMP N 05 Semarang peserta didik kelas IX setelah diberikan tes uraian. Tes evaluasi pembelajaran yang digunakan di sekolah belum mencakup keseluruhan penilaian kemampuan literasi sains, yaitu hanya mengukur tingkat pengetahuan. Berdasarkan permasalahan yang sudah dipaparkan, kemudian dilakukan penelitian untuk menganalisis miskonsepsi literasi sains menggunakan three tier multiple choice (3TMC) test pada materi cahaya. Instrumen ini dengan menambahkan tingkat ketiga yang meminta kepercayaan pada jawaban dan alasan yang diberikan sehingga mampu memahami bahwa peserta didik benar-benar paham, salah konsep atau menebak (Gurel et al., 2015).

Tujuan dari penelitian ini adalah

(1) Mengembangkan instrumen diagnostik 3TMC test dengan aspek literasi sains untuk menganalisis miskonsepsi literasi sains.

(2) Menemukan miskonsepsi literasi sains pada peserta didik.

\section{METODE PENELITIAN}

Penelitian dilakukan pada peserta didik kelas VIII di SMP N 05 Semarang yang terdiri dari 8 kelas. Secara random dipilih kelas VIII E dan VIII F sebagai sampel penelitian yang terdiri dari 61 peserta didik. Penelitian ini menggunakan metode campuran (mix method) rancangan strategi eksplanatoris sekuensial. Strategi diterapkan berurutan dengan pengumpulan dan analisis data kuantitatif tahap I, diikuti pengumpulan dan analisis data kualitatif tahap II yang dibangun berdasarkan hasil awal kuantitatif (Creswell, 2014). 


\section{Tahap I (pengumpulan data kuantitatif)}

Dokumentasi nilai UH (Ulangan Harian) materi cahaya kelas VIII tahun 2015/2016; soal UAS kelas VIII semester II (butir soal materi cahaya yang sulit dipahami peserta didik); data literasi sains PISA 2015; pembuatan soal uraian dan diujikan pada kelas IX tahun ajaran 2016/ 2017 untuk mengetahui kemungkinan ada atau tidaknya miskonsepsi pada peserta didik; dan pembuatan soal 3TMC test dengan aspek literasi sains.

Tahap selanjutnya yaitu penilaian validitas isi oleh ahli (satu dosen ahli dan dua guru mata pelajaran IPA); uji coba soal 3TMC test dengan aspek literasi sains; analisis reliabilitas, daya pembeda dan tingkat kesukaran butir soal; revisi perbaikan konten 3TMC test dengan aspek literasi sains; tahap uji lapangan kepada sampel penelitian; dan analisis hasil uji lapangan (data miskonsepsi literasi sains setiap butir soal dan setiap peserta didik). Angket penilaian diberikan kepada sampel uji coba untuk mengetahui penilaian peserta didik ditinjau dari segi konstruksi dan waktu pengerjaan, sedangkan pada uji lapangan diberikan angket respon untuk mengetahui konstruksi dan substansi soal 3TMC test dengan aspek literasi sains.

\section{Tahap II (pengumpulan data kualitatif)}

Wawancara mendalam dilakukan pada beberapa sampel penelitian dalam hal ini tujuh peserta didik dengan kriteria peserta didik yang mengalami miskonsepsi terbanyak. Hasil wawancara digunakan untuk mengetahui bentuk miskonsepsi literasi sains materi cahaya yang dialami peserta didik.

\section{HASIL DAN PEMBAHASAN}

\section{(1) Produk Hasil Pengembangan 3TMC Test Dengan Aspek Literasi Sains}

Pada penelitian ini pengembangan instrumen diagnostik 3TMC test dengan aspek literasi sains digunakan untuk mengungkap dan menemukan bentuk miskonsepsi literasi sains peserta didik. Hasil pengembangan produk 3TMC test dengan aspek literasi sains ini terdiri atas (1) kisi-kisi soal, (2) butir soal 3TMC test dengan aspek literasi sains, (3) kunci jawaban, (4) lembar jawab, (5) pedoman penskoran dan (6) pedoman interpretasi miskonsepsi literasi sains. Hasilnya instrumen diagnostik 3TMC test dengan aspek literasi sains yang memiliki karakteristik sebagai berikut:

(1) Setiap butir soal yang dikembangkan bertemakan aspek-aspek literasi sains 
terdiri atas empat aspek yaitu aspek pengetahuan sains (A), kompetensi dalam penyelidikan sains (B), sains sebagai cara berpikir (C), dan hubungan sains dengan teknologi, lingkungan dan masyarakat (D). Perbandingan butir soal aspek literasi sains menurut aturan yang dibuat Wilkinson (1999) dengan aspek A: B: C: D = 2: 1: 1: 1. Pada penelitian ini aspek pengetahuan sains (A) memiliki jumlah yang lebih banyak dari aspek literasi sains yang lain.

(2) Setiap butir soal yang dikembangkan terdiri atas tiga tingkatan. Tingkat pertama berupa soal pilihan ganda yang bertema literasi sains dengan satu kunci jawaban benar dan tiga butir pengecoh. Tingkat kedua merupakan alasan peserta didik menjawab pertanyaan, berupa tiga alasan yang telah disediakan dan satu alasan terbuka. Tingkat ketiga merupakan keyakinan peserta didik dalam memilih jawaban dan alasan yang terbagi menjadi enam skala (skala 1=menebak, $2=$ sangat tidak yakin, 3=tidak yakin, 4=cukup yakin, 5=yakin, dan $6=$ sangat yakin).

(3) Soal uji pelaksanaan instrumen 3TMC test dengan aspek literasi sains yang digunakan sebanyak 25 butir soal, terdiri atas 6 submateri cahaya dan 9 indikator pembelajaran. Subpokok bahasan materi cahaya terdiri atas sifat-sifat cahaya, cermin, lensa, bagian-bagian mata beserta fungsinya, cacat mata, dan alat optik.

(4) Pedoman penskoran instrumen 3TMC test terdiri atas penskoran pilihan jawaban, penskoran pilihan alasan dan kategori tingkat keyakinan. Penskoran jawaban dengan ketentuan skor $1=$ jawaban benar dan skor $0=$ jawaban yang salah atau tidak menjawab. Penskoran tersebut juga berlaku untuk penskoran kategori alasan. Adapun kategori tingkat keyakinan peserta didik termasuk kategori rendah (tingkat keyakinan skala 1-3), dan tingkat keyakinan tinggi (skala 4-6).

(5) Hasil tes yang telah dikerjakan oleh peserta didik dianalisis dan diinterpretasikan untuk mengetahui profil miskonsepsi literasi sains yang dialami peserta didik.

Pedoman interpretasi miskonsepsi literasi sains dapat dilihat pada Tabel 1. 
Hasil analisis reliabilitas menunjukkan bahwa butir soal pada instrumen 3TMC test dengan aspek literasi sains bersifat reliabel dengan nilai sebesar 0,773 artinya instrumen memiliki taraf kepercayaan yang tinggi.

Apabila instrumen diberikan untuk subjek yang sama tetapi waktunya berbeda maka memberikan hasil yang sama (Arikunto, 2012). Reliabilitas menyatakan sejauh mana hasil suatu pengukuran dapat dipercaya (Matondang, 2009). Hal ini berarti instrumen 3TMC test dengan aspek literasi sains yang dikembangkan memiliki keajegan dalam mengungkap miskonsepsi literasi sains peserta didik pada materi cahaya.

Butir soal 3TMC test dengan aspek literasi sains yang sudah dikembangkan berjumlah 30 soal. Soal tersebut dapat digunakan untuk diuji coba apabila telah teruji kevalidannya. Pada penelitian ini pengujian instrumen 3TMC test dengan aspek literasi sains menggunakan validitas isi oleh tiga validator untuk menerima saran perbaikan instrumen.

Tabel 1. Pedoman Interpretasi Miskonsepsi Literasi Sains

\begin{tabular}{llllcll}
\hline & \multicolumn{2}{c}{ Tipe respons } & & \\
\hline & Skwaban & Slasan & Skor & $\begin{array}{c}\text { Tingkat } \\
\text { Keyakinan }\end{array}$ & Skor & \\
\hline Benar & 1 & Benar & 1 & Tinggi & 1 & P \\
Benar & 1 & Benar & 1 & Rendah & 0 & TP \\
Benar & 1 & Salah & 0 & Rendah & 0 & TP \\
Salah & 0 & Benar & 0 & Rendah & 0 & TP \\
Salah & 0 & Salah & 0 & Rendah & 0 & TP \\
Salah & 0 & Salah & 0 & Tinggi & 1 & M \\
Salah & 0 & Benar & 1 & Tinggi & 1 & M \\
Benar & 1 & Salah & 0 & Tinggi & 1 & M \\
\hline
\end{tabular}

Keterangan: $\mathrm{P}=$ paham, $\mathrm{TP}=$ tidak paham, $\mathrm{M}=$ miskonsepsi

Hasil analisis penilaian validitas isi instrumen 3TMC test dengan aspek literasi sains termasuk ke dalam kategori sangat baik artinya instumen dapat digunakan untuk diuji coba. Penilaian dari validator digunakan untuk perbaikan pada instrumen 
diantaranya terkait dengan bacaan, kalimat soal, pilihan jawaban dan pilihan alasan yang tersedia.

Produk instrumen 3TMC test yang dikembangkan kemudian diuji cobakan kepada 30 responden yang sudah menerima pembelajaran materi cahaya. Hasil uji coba kemudian dianalisis reliabilitas, tingkat kesukaran dan daya pembeda butir soalnya.

Tabel 2. Kategori Tingkat Kesukaran Butir Soal

\begin{tabular}{lcl}
\hline TK & Nomor soal & Jumlah \\
\hline Mudah & $2,7,11,14,20,24,27,30$ & 8 \\
Sedang & $1,3,4,5,6,8,9,10,12,13,15,18,19,22,23$, & 18 \\
Sukar & $25,26,28$ & 4 \\
\hline
\end{tabular}

Keterangan: TK = Tingkat Kesukaran

Hasil analisis tingkat kesukaran menunjukkan bahwa keseluruhan soal mencakup soal mudah $27 \%$, sedang $60 \%$ dan sukar $13 \%$. Sebagian besar soal yang dikembangkan termasuk ke dalam kriteria sedang. Kriteria soal diagnostik yang baik adalah soal yang tidak terlalu mudah atau tidak terlalu sukar (Arikunto, 2012; Fariyani et al., 2015). Soal yang terlalu mudah tidak dapat merangsang peserta didik untuk mempertinggi usahanya, sedangkan soal yang terlalu sukar menyebabkan peserta didik menjadi putus asa dalam mengerjakan dan tidak mempunyai semangat untuk mencoba lagi (Arikunto, 2012).

Tabel 3. Kategori Daya Pembeda Butir Soal

\begin{tabular}{lll}
\hline DP & Nomor soal & Jumlah \\
\hline Baik & $1,2,5,6,10,11,13,14,22,24,27,28,30$ & 13 \\
Cukup & $3,4,7,8,9,15,18,19,20,23,25,26$ & 12 \\
Jelek & $12,16,17,21,29$ & 5 \\
\hline
\end{tabular}

Keterangan: DP $=$ Daya Pembeda

Analisis butir soal selanjutnya adalah daya pembeda butir soal. Soal dengan daya pembeda baik dan cukup artinya butir soal dapat membedakan antara peserta didik yang menguasai dan tidak menguasai materi (Arikunto, 2012). Hasil analisis menunjukkan 
dari 30 butir soal terdapat 4 butir soal yang memiliki daya pembeda jelek. Butir soal yang memiliki daya pembeda jelek sebaiknya tidak digunakan untuk uji lapangan.

Hasil analisis validasi isi, reliabilitas, tingkat kesukaran dan daya pembeda butir soal pada instrumen 3TMC test digunakan untuk menentukan butir soal mana saja yang dapat digunakan untuk uji lapangan. Butir soal yang digunakan untuk menganalisis miskonsepsi literasi sains adalah yang memenuhi kriteria valid, reliabel, daya pembeda (cukup atau baik), dan tingkat kesukaran (mudah atau sedang). Tes diagnostik yang dikembangkan oleh Udompong \& Wongwanich (2014) termasuk ke dalam kategori baik dalam hal reliabilitas, tingkat kesukaran, daya pembeda dan validitas isinya.

Hasilnya dari 30 butir soal uji coba, yang bisa digunakan untuk uji lapangan adalah 25 butir soal. Aspek pengetahuan sains berjumlah 10 butir soal, dan 5 butir soal untuk masing-masing aspek sains sebagai cara berpikir, kompetensi dalam penyelidikan sains, dan aplikasi sains dengan teknologi, masyarakat dan lingkungan. Perbaikan tetap dilakukan pada 25 butir soal yang akan digunakan untuk uji lapangan dari segi konstruksi maupun segi isi soal yang disesuaikan dengan kebutuhan perbaikan. Adapun hasil angket penilaian peserta didik dengan kategori baik dan sangat baik, artinya instrumen 3TMC test dengan aspek literasi sains dapat digunakan tanpa revisi.

\section{(2) MISKONSEPSI LITERASI SAINS}

\section{a) Interpretasi miskonsepsi literasi sains}

Produk instrumen diagnostik 3TMC test dengan aspek literasi sains yang sudah direvisi digunakan untuk menguji miskonsepsi literasi sains pada 61 peserta didik. Tes diberikan pada sampel di akhir pembelajaran setelah menerima pembelajaran materi cahaya. Hasilnya dianalisis untuk membedakan peserta didik yang paham, tidak paham atau mengalami miskonsepsi literasi sains. Miskonsepsi literasi sains pada setiap peserta didik dapat dilihat pada Tabel 4. berikut.

Tabel 4. menunjukkan bahwa seluruh peserta didik mengalami miskonsepsi materi cahaya terjadi pada seluruh aspek literasi sains. Miskonsepsi literasi sains pada aspek pengetahuan sains (A) disebabkan karena pengetahuan sains dianggap sebagai batang tubuh dalam sains, artinya menjadi dasar pentingnya memahami sains (Chiappetta et al., 1991; Boujaoude, 2002; Dani, 2009; Budiningsih et al., 2015; Rusilowati et al., 2016). Pada proses pembelajaran sains guru perlu melengkapi peserta didik dengan pengetahuan dasar sains. 
Miskonsepsi literasi sains pada aspek kompetensi dalam penyelidikan sains (B) dan aspek sains sebagai cara berpikir (C). Pada proses pembelajaran sains peserta didik harus memahami keterampilan penyelidikan sains termasuk proses sains (metode ilmiah) sehingga dapat mengembangkan sikap ilmiah dan keterampilan berpikirnya (Maturradiyah \& Rusilowati, 2015). Adanya kegiatan penyelidikan ilmiah akan menumbuhkan kemampuan berpikir kritis dari peserta didik, artinya apabila kompetensi dalam penyelidikan sains peserta didik rendah maka keterampilan berpikir kritisnya juga rendah.

Tabel 4. Hasil Analisis Miskonsepsi Literasi Sains

\begin{tabular}{|c|c|c|c|c|c|c|c|c|c|c|c|c|c|c|c|}
\hline \multirow{3}{*}{ Kode PD } & \multicolumn{7}{|c|}{ Jumlah } & \multirow{3}{*}{ Kode PD } & \multicolumn{7}{|c|}{ Jumlah } \\
\hline & \multicolumn{3}{|c|}{$\begin{array}{l}\text { Miskonsepsi } \\
\text { Literasi Sains } \\
\end{array}$} & \multirow{2}{*}{$\frac{\mathrm{M}}{\mathrm{D}}$} & \multirow[t]{2}{*}{$\mathrm{P}$} & \multicolumn{2}{|c|}{$\mathrm{TP}$} & & \multicolumn{4}{|c|}{$\begin{array}{l}\text { Miskonsepsi } \\
\text { Literasi Sains }\end{array}$} & \multirow[t]{2}{*}{$\mathrm{M}$} & \multirow[t]{2}{*}{$\mathrm{P}$} & \multirow[t]{2}{*}{$\mathrm{TF}$} \\
\hline & $\mathrm{A}$ & B & $\mathrm{C}$ & & & & & & $\mathrm{A}$ & B & C & $\mathrm{D}$ & & & \\
\hline B1 & 2 & 1 & 2 & 2 & 7 & 7 & 11 & $\mathrm{C} 1$ & 7 & 4 & 3 & 3 & 17 & 8 & 0 \\
\hline B2 & 4 & 0 & 0 & 0 & 4 & 6 & 15 & $\mathrm{C} 2$ & 0 & 1 & 1 & 0 & 2 & 7 & 16 \\
\hline B3 & 7 & 2 & 2 & 2 & 13 & 8 & 4 & C3 & 5 & 1 & 4 & 0 & 10 & 4 & 11 \\
\hline B4 & 4 & 2 & 3 & 1 & 10 & 15 & 0 & C4 & 3 & 2 & 2 & 2 & 9 & 12 & 4 \\
\hline B5 & 4 & 2 & 2 & 3 & 11 & 6 & 8 & C5 & 7 & 2 & 4 & 5 & 18 & 2 & 5 \\
\hline B6 & 1 & 0 & 0 & 0 & 1 & 3 & 21 & C6 & 4 & 0 & 1 & 0 & 5 & 4 & 16 \\
\hline B7 & 8 & 2 & 1 & 1 & 12 & 6 & 7 & C7 & 7 & 2 & 2 & 2 & 13 & 10 & 2 \\
\hline B8 & 5 & 2 & 4 & 0 & 11 & 13 & 1 & $\mathrm{C} 8$ & 7 & 3 & 3 & 2 & 15 & 7 & 3 \\
\hline B9 & 2 & 0 & 3 & 0 & 5 & 9 & 11 & C9 & 3 & 2 & 2 & 1 & 8 & 7 & 10 \\
\hline B10 & 3 & 1 & 2 & 0 & 6 & 14 & 5 & $\mathrm{C} 10$ & 4 & 0 & 0 & 1 & 5 & 10 & 10 \\
\hline B11 & 1 & 4 & 1 & 2 & 8 & 14 & 3 & $\mathrm{C} 11$ & 2 & 0 & 1 & 0 & 3 & 9 & 13 \\
\hline B12 & 3 & 2 & 3 & 2 & 10 & 10 & 5 & $\mathrm{C} 12$ & 5 & 1 & 1 & 1 & 8 & 4 & 13 \\
\hline B13 & 5 & 2 & 2 & 1 & 10 & 11 & 4 & $\mathrm{C} 13$ & 1 & 1 & 1 & 1 & 4 & 4 & 17 \\
\hline B14 & 3 & 2 & 0 & 1 & 6 & 10 & 9 & C14 & 2 & 1 & 0 & 0 & 3 & 8 & 14 \\
\hline B15 & 7 & 2 & 3 & 3 & 15 & 10 & 0 & C15 & 2 & 0 & 0 & 0 & 2 & 9 & 14 \\
\hline B16 & 7 & 2 & 1 & 2 & 12 & 7 & 6 & $\mathrm{C} 16$ & 2 & 0 & 0 & 0 & 2 & 4 & 19 \\
\hline B17 & 7 & 0 & 4 & 4 & 15 & 3 & 7 & $\mathrm{C} 17$ & 3 & 2 & 2 & 2 & 9 & 7 & 9 \\
\hline B18 & 2 & 2 & 2 & 1 & 7 & 11 & 7 & $\mathrm{C} 18$ & 2 & 1 & 1 & 0 & 4 & 11 & 10 \\
\hline B19 & 2 & 3 & 2 & 1 & 8 & 17 & 0 & C19 & 2 & 0 & 1 & 0 & 3 & 6 & 16 \\
\hline B20 & 1 & 2 & 1 & 1 & 5 & 7 & 13 & C20 & 2 & 1 & 1 & 0 & 4 & 12 & 9 \\
\hline B21 & 4 & 1 & 1 & 1 & 7 & 8 & 10 & C21 & 5 & 2 & 0 & 2 & 9 & 7 & 9 \\
\hline B22 & 6 & 3 & 3 & 1 & 13 & 7 & 5 & $\mathrm{C} 22$ & 4 & 3 & 3 & 4 & 14 & 8 & 3 \\
\hline B23 & 3 & 0 & 0 & 1 & 4 & 15 & 6 & $\mathrm{C} 23$ & 0 & 0 & 1 & 0 & 1 & 1 & 23 \\
\hline B24 & 3 & 0 & 1 & 1 & 5 & 7 & 13 & $\mathrm{C} 24$ & 5 & 4 & 2 & 1 & 12 & 9 & 4 \\
\hline B25 & 4 & 2 & 1 & 1 & 8 & 4 & 13 & C25 & 5 & 2 & 2 & 2 & 11 & 10 & 4 \\
\hline B26 & 6 & 2 & 2 & 1 & 11 & 9 & 5 & $\mathrm{C} 26$ & 6 & 3 & 5 & 3 & 17 & 8 & 0 \\
\hline B27 & 9 & 3 & 2 & 2 & 16 & 7 & 2 & C27 & 3 & 2 & 1 & 4 & 10 & 5 & 10 \\
\hline B28 & 1 & 1 & 1 & 1 & 4 & 14 & 7 & $\mathrm{C} 28$ & 3 & 4 & 2 & 2 & 11 & 10 & 4 \\
\hline B29 & 1 & 0 & 2 & 1 & 4 & 4 & 17 & C29 & 2 & 1 & 2 & 0 & 5 & 3 & 17 \\
\hline B30 & 3 & 1 & 0 & 1 & 5 & 6 & 14 & C30 & 4 & 1 & 2 & 2 & 9 & 9 & 7 \\
\hline
\end{tabular}

Keterangan: $\mathrm{M}=$ Miskonsepsi, $\mathrm{P}=$ Paham, $\mathrm{TP}=$ Tidak Paham 
Kebiasan pembelajaran sains di sekolah yang lebih menekankan pada aspek kognitif bukan mengembangkan keterampilan berpikir peserta didik. Artinya proses pemerolehan pengetahuan sains kurang melibatkan kompetensi dalam penyelidikan sains dan kemampuan berpikir kritis peserta didik. Keterampilan proses sains peserta didik dapat ditingkatkan melalui kegiatan praktikum dan presentasi hasil praktikum (Hindarto, 2009). Kegiatan laboratorium dapat meningkatkan kemampuan literasi sains peserta didik pada dimensi proses sains (Permatasari et al., 2014). Pentingnya dalam membelajarkan sains secara seimbang antara abstract conceptualization dan active experimentation (Rusilowati, 2014).

Terjadinya miskonsepsi pada aspek B dan C karena peserta didik (1) jarang melakukan kegiatan laboratorium; (2) tidak memahami istilah-istilah dalam beberapa kegiatan penyelidikan ilmiah seperti variabel terikat dan variabel bebas; (3) lebih banyak menghabiskan waktu untuk menghafal dalam belajar sains (Rusilowati et al., 2016). Pembelajaran sains sebaiknya lebih menekankan pada aktivitas dan belajar aktif bagi peserta didik, menekankan keterampilan proses sains untuk merumuskan konsep, mengurangi hafalan, dan banyak melakukan kegiatan di laboratorium atau kerja lapangan (Leonard, 1993 dalam Maturradiyah \& Rusilowati, 2015). Membiasakan peserta didik untuk menganalisis soal-soal berliterasi sains, diskusi, menganalisis bukti ilmiah, mengevaluasi data dan membuat kesimpulan dapat meningkatkan keterampilan berpikir kritis peserta didik (Permatasari et al., 2014; Odja \& Payu, 2014).

Miskonsepsi literasi sains juga terjadi pada aspek aplikasi sains atau hubungan sains, teknologi, masyarakat dan lingkungan (D). Peserta didik tidak memahami tentang aplikasi sains dan hubungannya dengan teknologi, masyarakat dan lingkungan serta menggunakan pengetahuan sains yang sesuai dengan moral dan tingkah laku. Udompong \& Wongwanich (2014) menyatakan bahwa peserta didik mengalami miskonsepsi literasi sains pada aspek konteks, dimana aspek konteks dalam PISA 2009 termasuk dalam aspek aplikasi sains dan hubungannya dengan SETS. Aspek aplikasi sains (D) termasuk dalam kategori kemampuan multidimensional yaitu memanfaatkan berbagai konsep dan menunjukkan kemampuan untuk menghubungkan konsep dengan kehidupan sehari-hari, memahami bahwa sains, sosial dan teknologi saling terkait dan mempengaruhi satu sama lain (Odja \& Payu, 2014). 
Adapun respon peserta didik terhadap instrumen 3TMC test dengan aspek literasi sains dengan kategori sangat baik dan baik artinya instrumen dapat digunakan untuk menganalisis miskonsepsi literasi sains.

\section{b) Miskonsepsi literasi sains materi cahaya}

Adapun miskonsepsi literasi sains setiap butir soal dikategorikan menjadi tiga yaitu miskonsepsi tinggi, sedang dan rendah (Fariyani et al., 2015). Kategori miskonsepsi literasi sains pada penelitian ini sebagai berikut:

$$
\begin{array}{ll}
\text { Miskonsepsi rendah } & \text { : } 0 \% \leq \mathrm{M}<30 \% \\
\text { Miskonsepsi sedang } & : 30 \% \leq \mathrm{M}<60 \% \\
\text { Miskonsepsi tinggi } & : 60 \% \leq \mathrm{M} \leq 100 \%
\end{array}
$$

Hasilnya tujuh peserta didik dengan miskonsepsi tinggi yaitu kode B15, B17, B27, C1, C5, C8. Ketujuh peserta didik dilakukan wawancara mendalam untuk mengetahui bentuk miskonsepsi literasi sains materi cahaya. Hasil wawancara menunjukkkan bahwa peserta didik mengalami miskonsepsi literasi sains sifat-sifat cahaya antara lain (a) hukum pemantulan cahaya hanya berlaku pada permukaan yang datar atau rata; (b) sinar pantul pada permukaan kasar memiliki sudut datang $\neq$ sudut pantul; (c) garis bantu atau garis normal selalu menghadap ke atas, bukan tegak lurus permukaan pantul; (d) balok besi yang tercelup di kolam terlihat lebih dekat karena balok besi mengalami peristiwa pembiasan; (e) cahaya yang melewati dua medium berbeda pasti dibelokkan, bagaimanapun posisi arah datangnya cahaya; (f) pembiasan dapat terjadi jika cahaya tegak lurus pada bidang permukaan; (g) semakin rapat suatu medium, maka perambatan cahaya juga semakin cepat; (h) udara merupakan medium yang memiliki kerapatan paling besar; (i) persepsi peserta didik dalam mengartikan cahaya diuraikan sama dengan menyebar; dan (j) cahaya memiliki sifat yaitu menyebar seperti pada lampu, senter dan cahaya matahari.

Pemantulan cahaya merupakan salah satu miskonsepsi yang paling banyak ditemui di materi cahaya sesuai dengan hasil penelitian Fariyani et al. (2015) dan Aydin (2012). Hasil penelitian Caleon \& Subramaniam (2010) menunjukkan bahwa sifat pembiasan cahaya merupakan salah satu indikator yang banyak mengalami miskonsepsi oleh peserta didik. 
Bentuk miskonsepsi literasi sains peserta didik lainnya kemampuan melihat benda apabila ada cahaya mengenai mata dan dipantulkan ke benda; warna adalah milik benda bukan hasil dari cahaya yang dipantulkan benda. Hal ini sesuai dengan penelitian yang dilakukan oleh Djanette \& Fouad (2014) yang menyatakan bahwa warna adalah milik benda dan mata yang memberi warna pada benda.

Bentuk miskonsepsi literasi sains tentang cacat mata antara lain peserta didik memahami rabun dekat, merupakan cacat mata yang bisa melihat benda dekat; rabun jauh, merupakan cacat mata yang bisa melihat benda jauh dengan jelas; rabun dekat berarti pembentukan bayangan di depan retina; rabun jauh berarti pembentukan bayangan di belakang retina. Hasil yang sama juga disampaikan oleh Fariyani et al. (2015) yang menyatakan bahwa bayangan akan jatuh di depan retina pada penderita cacat mata hipermetropi (rabun dekat).

Miskonsepsi literasi sains pada alat optik lup antara lain menggunakan lensa cembung dengan nama lain lensa bikonkaf, fungsi lup untuk melihat benda mikroskopis. Sedangkan miskonsepsi literasi sains pada bagian dan fungsi mata antara lain diafragma merupakan bagian dari mata; pupil mengecil pada suasana gelap karena cahaya di sekitar sedikit; diafragma dan pupil adalah bagian organ yang memiliki fungsi yang sama; mata serangga berjumlah dua buah; lensa mata menebal karena adanya relaksasi otot siliaris pada daya akomodasi maksimum; lensa mata memipih karena adanya kontraksi otot siliaris pada daya akomodasi minimum; kontak lensa sebagai pengganti kornea; kornea memiliki pigmen warna.

\section{SIMPULAN}

Hasil pengembangan instrumen diagnostik 3TMC test dengan aspek literasi sains yaitu soal yang memuat aspek literasi sains dengan perbandingan setiap aspek 2: 1: 1: 1 dengan jumlah 25 butir soal. Setiap butir soal terdiri dari tiga tingkatan dengan tingkat pertama berupa pertanyaan dengan empat pilihan jawaban, tingkat kedua berupa tiga pilihan alasan yang disediakan dan satu alasan terbuka, sedangkan tingkat ketiga berupa tingkat keyakinan dengan skala 1 (menebak), 2 (sangat tidak yakin), 3 (tidak yakin), 4 (yakin), 5 (cukup yakin), dan 6 (sangat yakin). Hasil analisis butir dan validasi menunjukkan bahwa butir soal 3TMC test dengan aspek literasi sains bersifat valid, reliabel, tingkat kesukaran baik dengan rata-rata berkategori sedang, dan daya pembeda 
soal berkategori baik.

Adapun hasil interpretasi miskonsepsi menunjukkan bahwa peserta didik mengalami miskonsepsi literasi sains pada aspek pengetahuan (A), aspek kompetensi dalam penyelidikan sains (B), aspek sains sebagai cara berpikir (C) dan aspek aplikasi sains terhadap teknologi, masyarakat dan lingkungan (D). Hasil wawancara mendalam terhadap 7 peserta didik dengan miskonsepsi tertinggi diperoleh miskonsepsi literasi sains pada materi cahaya pada submateri sifat-sifat cahaya, proses melihat, cacat mata dan jenis serta fungsi alat optik. 


\section{DAFTAR PUSTAKA}

Alchin, D. 2014. From Science Studies to Scientific Literacy: A View From The Class. Scie \& Educ, 23(9): 1911-1932.

Arikunto, S. 2012. Dasar-Dasar Evaluasi Pendidikan. Jakarta: PT Bumi Aksara.

Aydin, S. 2012. Remidiation Of Misconceptions About Geometric Optics Using Conceptual Change Texts. Journal of Education Research And Behavioral Sciences, 1(1): 1-12.

Boujaoude, S. 2002. Balance of Science Literacy Themes in Science Curricula: The Case of Lebanon. International Journal of Science Education, 24(2): 139-156.

Budiningsih, T. Y., Rusilowati, A., \& Marwoto, P. 2015. Pengembangan Buku Ajar IPA Terpadu Berorientasi Literasi Sains Materi Energi dan Suhu.Journal of Innovative Science Education, 4(2): 34-40.

Caleon, I. S. \& Subramaniam, R. 2010. Development and Aplication of Three Tier Diagnostic Test to Assess Secondary Students' Understanding of Waves. International Journal of Science Education, 7(1): 939-961.

Chiappetta, E. L., Filman, D. A., \& Sethna, G. H. 1991. A Method to Quantify Major Themes of Scientific Literacy in Science Textbooks. Journal of Research in Science Teaching, 28(8): 713-725.

Clement, J., Brown, D. E., \& Zietsman, A. 1989. Not Al Preconceptions are Misconceptions: Finding 'Anchoring Conceptions' for Grounding Instruction on Students' Intuitions. International Journal of Science Education, 27(3): 253-265.

Creswell, J. W. 2014. Research Design Pendekatan Kuantitatif, Kualitatif dan Mixed. Yogyakarta: Pustaka Pelajar.

Dani, D. 2009. Scientific Literacy And Purposes For Teaching Science: A Case Study Of Lebanese Private School Teachers. International Journal of Environmental and Science Education, 4(3): 289-299.

Djanette, B., \& Fouad, C. 2014. Determination of University Student's Misconceptions about Light using Concept Maps. Procedia-Social and Behavioral Sciences, 152(1): 582-589.

Fariyani, Q., Rusilowati, A., \& Sugianto. 2015. Pengembangan Four-Tier Diagnostic Test untukMengungkap Miskonsepsi Fisika Siswa SMA Kelas X. Journal of Innovative Science Education, 4(2), 41-49.

Franke, G., Scharfenberg, F. J., \& Bogner, F. X. 2013. Research Articel Investigation of Students Alternative Conceptions of Terms and Processes of Gene Technology. ISRN Education, 2013:1-13.

Gurel, D. K., Ali, E., \& Lilian, C.M. 2015. A Review and Comparison of Diagnostic Instruments to Identify Students' Misconceptions in Science.Eurasia J. Math. Sci. \& Tech. Ed., 11(5), 989-1008.

Hindarto, N. 2009. Dampak Pelatihan Guru Pemandu Bidang Studi IPA terhadap Pembelajaran IPA di Sekolah Dasar. Jurnal Pendidikan Dasar, 10(2): 190-195. 
Ma'muroh, H., Asrizal.,\& Zulhendri, K. 2014. Pembuatan Instrumen Evaluasi Pembelajaran IPA Terpadu berbasis ICT Untuk Mengukur Kompetensi Siswa SMP Kelas VIII. Phylar of Physic Education, 1(3): 41-48.

Matondang, Z. 2009. Validitas dan Reliabilitas Suatu Penelitian. Jurnal Tabularasa PPs Unimed, 6(1): 87-97.

Maturradiyah, N., \& Rusilowati, A. 2015.Analisis Buku Ajar Fisika SMA Kelas XII di Kabupaten Pati Berdasarkan Muatan Literasi Sains. Unnes Physics Education Journal, 4(1): 16-20.

Odja, A. H. \& Payu, C. S. 2014. Analisis Kemampuan Awal Literasi Sains Siswa Pada Konsep IPA. Prosiding Seminar Nasional Kimia. Surabaya: Universitas Negeri Surabaya.

OECD. 2016a. PISA 2015 Assessment and Analytical Framework Science, Reading, Mathematic and Financial Literacy. Paris: OECD Publications.

OECD. 2016b. PISA Result in Focus. Paris: OECD Publications.

Permatasari, O. I., Rusilowati, A. \& Masturi. 2014. Developing Science Learning Materials for Junior High School Based on Way of Investigating to Improve Scientefic Literacy. ICMSE, (1-5).

Rusilowati, A. 2013. Peningkatan Literasi Sains Siswa melalui Pengembangan Instrument Penilaian. Pidato Pengukuhan Profesor Bidang Evaluasi Pendidikan Fakultas Matematika dan Ilmu Pengetahuan Alam Universitas Negeri Semarang.

Rusilowati. 2014. Analisis Buku Ajar IPA yang Digunakan Di Semarang Berdasarkan Muatan Literasi Sains. Prosiding Seminar Nasional Konservasi dan Kualitas Pendidikan, 6-10. Semarang: UNNES.

Rusilowati, A., Kurniawati, L., Nugroho, S. E., \& Widiyatmoko, A. 2016. Developing an Instrumen of Scientific Literacy Asessment on The Cycle Theme. International Journal of Enviromental \& Science Education, 11(12): 5718-5727.

Sari, D. M., Surantoro.,\& Ekawati, E. Y. 2013. Analisis Kesalahan dalam Menyelesaikan Soal Materi Termodinamika pada Siswa SMA. Jurnal Materi dan Pembelajaran Fisika, 3(1): 5-8.

Taufiq, M. 2012. Remediasi Miskonsepsi Mahasiswa Calon Guru Fisika padaKonsep Gaya melalui Penerapan Model Siklus Belajar(Learning Cycle) 5E. Journal Pendidikan IPA Indonesia, 1(2), 198-203.

Udompong, L. \& Wongwanich, S. 2014. Diagnosis of the Scientific Literacy Characteristic of Primary Students. Procedia-Social and Behavioral Sciences, 116(1): 5091-5096.

Wilkinson, J. 1999. A Quantitative Analysis of Physics Textbooks for Scientific Literacy Themes. Research in Science Education, 29(3): 385-399. 